\title{
Dry Eye Treatments and Preference Survey
}

William $\mathrm{CS}^{1 *}$, Henry $\mathrm{H}^{2}$, Jeanette $\mathrm{AS}^{1}$ and Lindsay $\mathrm{AN}^{1}$

${ }^{1} P R N$ Pharma Farm, LLC, Cheyenne, USA

${ }^{2}$ Allysta Pharmaceuticals, Inc., Hillsborough, USA

*Corresponding author: William CS, PRN Pharma Farm, LLC, Cheyenne, USA, E-mail: info@prnorb.com

Received date: April 25, 2018; Accepted date: May 9, 2018; Published date: May 19, 2018

Copyright: $\bigcirc 2018$ William CS, et al. This is an open-access article distributed under the terms of the Creative Commons Attribution License, which permits unrestricted use, distribution, and reproduction in any medium, provided the original author and source are credited.

\author{
Abstract \\ Purpose: To survey ophthalmologists regarding their current therapy preferences and desires for future treatment \\ to help guide providers in choosing treatments and pharmaceutical startups in developing future therapies.
}

Methods: A prospective survey developed internally and sent twice to ophthalmologists.

Results: There were 76 responses. Approximately $30 \%$ of respondents stated they examined a few cases of dry eye disease (DED) patients a day and $20 \%$ noted DED was a majority of their practice. Almost all physicians recommended tear replacement drops (95\%) for their patients while $80 \%$ prescribed cyclosporine. Importantly, $40 \%$ started prescribing lifitegrast and the same percent prescribe tetracycline. When asked what new mechanisms of action physicians preferred, about $70 \%$ indicated improved tear film stability, while $50 \%$ desired greater lacrimal gland tear production. Further, $70 \%$ of physicians noted they would prescribe a product that increased tear film stability as first line. With two anti-inflammatory DED products currently available $55 \%$ of participants noted a third product should have a different mechanism of action while $25 \%$ desired better anti-inflammatory activity. In evaluating the available DED medications specifically, participants believed cyclosporine and lifitegrast had similar moderate levels of efficacy; with lifitegrast being slightly better tolerated than cyclosporine.

Conclusions: The survey showed that DED patients are an important part of the ophthalmic practice. Multiple different therapeutic techniques are used and there is desire for new products that especially would treat tear film stability and corneal surface disease.

Keywords: Dry eye disease; Startups; Development; Therapies; Treatments

\section{Introduction}

Dry eye disease (DED) continues to be an important part of ophthalmic related pathology as well as a target for new treatment products. DED afflicts a significant part of the adult population (6\%-34\%) [1-4]. Symptoms can be irritating, causing reduced quality of life, visual disturbance and pain [5].

Treatment modalities are multiple with no precise standard of care although helpful guidelines are available [5]. Two anti-inflammatory topical medications, cyclosporine (Restasis ${ }^{\mathrm{mi}}$ ) and lifitegrast (Xiidra $\left.{ }^{\mathrm{TH}}\right)$, as well as tear replacement drops are effective and commonly used. However, none of the available treatments are completely curative or prevent symptoms. Accordingly, at least 77 DED related products have been under development over the last number of years that have publicly available information including 12 active compounds with new mechanisms of action that is not currently available as well as a variety of tear replacement formulations and delivery systems [6]. Despite so many DED patients in the population, and diverse treatments available, little information exists on physician attitudes in treating DED both in terms of current practices and future treatment.

The purpose of this study was to survey ophthalmologists regarding their current therapy preferences and desires for future treatment. It is hoped this information would help guide providers in choosing current treatments and pharmaceutical startups in developing future therapies.

\section{Methods}

The design was a prospective survey of ophthalmologists. We used an existing internal, proprietary diverse database of ophthalmic physicians $(n=1837)$. The survey was sent to each physician in the database. Invitations were sent October 25, 2016 and reminders were sent November 10, 2016. Survey questions were developed internally, and the survey was linked through Survey Monkey (www.surveymonkey.com). A copy of the survey questions can be found online (supplemental).

\section{Results}

Of 1837 surveys sent, $76(4.2 \%)$ responded. Please see the full survey online (supplemental material). Approximately $70 \%(n=56)$ of the respondents had been in practice for more than 20 years. About $50 \%(n=36)$ were in a private group practice and $24 \%(n=18)$ at a university. The most common subspecialty was glaucoma at $42 \%$ $(n=32)$ while $26 \%(n=20)$ indicated they were anterior segment. Of the total, around $40 \%(\mathrm{n}=29)$ practiced comprehensive ophthalmology.

Approximately $30 \%(n=22)$ of respondents stated they examined a few cases of DED patients a day while $25 \%(n=19)$ indicated it was an important minority of their practice. However, $21 \%(n=16)$ noted DED was a majority of their practice. 
Almost all physicians recommended tear replacement drops ( $96 \%$ $\mathrm{n}=73)$ for their patients while almost $80 \% \quad(\mathrm{n}=59)$ prescribed cyclosporine. Three quarters of physicians use punctal occlusion $(n=48)$ and separately corticosteroids $(n=49)$ while $55 \% \quad(n=42)$ prescribe eyelid therapy. Importantly, around $40 \%(n=31)$ have started prescribing lifitegrast and the same percent prescribe tetracycline $(n=29)$. Other treatment methods are less commonly used (Table 1).

\begin{tabular}{|l|l|}
\hline Responses & Percentage \\
\hline Tear replacement drops & $96 \%$ \\
\hline Cyclosporine & $78 \%$ \\
\hline Punctal occlusion & $66 \%$ \\
\hline $\begin{array}{l}\text { Corticosteroids/other anti-inflammatory } \\
\text { agents }\end{array}$ & $64 \%$ \\
\hline Eyelid therapy & $55 \%$ \\
\hline Lifitegrast & $41 \%$ \\
\hline Tetracycline & $38 \%$ \\
\hline Serum & $28 \%$ \\
\hline Contact lenses & $12 \%$ \\
\hline Surgery & $12 \%$ \\
\hline Systemic immunosuppressant & $7 \%$ \\
\hline Pilocarpine & $5 \%$ \\
\hline Other & $3 \%$ \\
\hline
\end{tabular}

Table 1: Treatment options considered for DED patients (respondents could choose all that apply)

\begin{tabular}{|l|l|}
\hline Responses & Percentage \\
\hline Improved tear film stability & $72 \%$ \\
\hline Enhanced tear production & $53 \%$ \\
\hline Anything that helps! & $42 \%$ \\
\hline $\begin{array}{l}\text { Better anti-inflammatory CD4 }{ }^{+} \text {T cell } \\
\text { inhibition } \\
\text { cyclosporine, lifitegrast) }\end{array}$ & $42 \%$ \\
\hline Anti-inflammatory cytokine inhibition & $39 \%$ \\
\hline Epithelial healing/protection & $39 \%$ \\
\hline Greater mucin preservation & $34 \%$ \\
\hline Antioxidant activity & $11 \%$ \\
\hline Unsure & $4 \%$ \\
\hline
\end{tabular}

Table 2: If more medicines become available what actions would you like to see? (respondents could choose up to 3 they consider most important)

When asked what new mechanisms of action participants preferred, about $70 \%(\mathrm{n}=55)$ indicated improved tear film stability, while $50 \%$ $(\mathrm{n}=40)$ desired greater lacrimal gland tear production. Also, about $40 \%$ each wanted augmented anti-cytokine activity $(n=30)$, overall better anti-inflammatory activity $(\mathrm{n}=32)$ and improved epithelial surface healing $(\mathrm{n}=30$, Table 2$)$.

Further, approximately $70 \%(n=52)$ of physicians noted they would prescribe first line a product that increased tear film stability. In addition, for a medicine that improved epithelial healing $(n=32)$, or augmented tear film production $(n=33)$, they would prescribe first line such a medicine around $50 \%$ of the time respectively.

With two anti-inflammatory DED products currently available around $55 \%(n=42)$ of participants noted a third product should have a different mechanism of action while close to $25 \%(n=21)$ desired better anti-inflammatory activity.

In evaluating the two currently available DED medications specifically, participants believed cyclosporine and lifitegrast had similar moderate levels of efficacy. However, physicians thought lifitegrast was slightly better tolerated than cyclosporine. Regarding the new product lifitegrast, $40 \%$ of physicians stated they either already prescribed it $(n=30)$ or planned to prescribe $(n=26)$.

\section{Discussion}

The survey showed that DED patients are generally an important part of the practice of responding physicians. They indicated they used multiple different therapeutic techniques especially including: tear replacement drops, anti-inflammatory medications, punctual occlusion and eyelid therapy.

Despite these available treatments, these ophthalmologists desired new medicines that especially would be a different mechanism of action or have greater anti-inflammatory effect than the two medicines currently available, which are viewed as modest to moderately effective.

Preferred new mechanisms of action were greater tear film stability, improved corneal surface healing and an enhanced anti-inflammatory effect. A product with such actions would be prescribed by respondents as first line therapy approximately $50 \%$ of the time or more. These study results help confirm the usage and perceived desirability of current modalities for treating dry eye. However, the survey also emphasizes the need for new treatments that would perhaps help bring resolution to the disease or at least further reduce signs and symptoms without ocular surface irritation. We are fortunate that a number of new companies are working to bring new products with novel mechanisms to further assist patients in the future.

This survey was limited by the slightly low response rate and so may not represent fully the opinions of the ophthalmic community. Further the survey format limits the depth and number of questions which can be used. The survey length we limited because of the uncompensated and the business of medical practitioners. In contrast, a focus group setting could have allowed a more in-depth solicitation of viewpoints over DED. In addition, the new medication lifitegrast has been on the market a short period and impressions for this product might change over time. However, the survey, taken from a wide geographic area and diverse specialties should at least reflect the opinions of ophthalmologists regarding DED treatment and is a start to gaining information on this important topic.

This study provides insight to ophthalmologists' treatment patterns in DED and preferences for future therapy. Respondents currently utilize a wide menu of techniques to treat DED. Further, consideration could be given to the use of 'care managers' to assist patient planning 
and help compliance in DED. These efforts might lower treatment costs [7]. However, they desire new products that especially would treat tear film stability and corneal surface disease.

\section{References}

1. McCarty CA, Bansal AK, Livingston PM, Stanislavsky YL, Taylor HR (1998) The epidemiology of dry eye in Melbourne. Ophthalmology 105: 1114-1119.

2. Lin PY, Tsai SY, Cheng CY, Liu J-H, Chou P, et al. (2003) Prevalence of dry eye among an elderly Chinese population in Taiwan: the Shihpai Eye Study. Ophthalmology 110: 1096-1101.

3. Paulsen AJ, Cruickshanks KJ, Fischer ME, Huang GH, Klein BE, et al. (2014) Dry eye in the beaver dam offspring study: prevalence, risk factors, and health-related quality of life. Am J Ophthalmol 157: 799-806.
4. Schaumberg DA, Sullivan DA, Buring JE, Dana MR (2003) Prevalence of dry eye syndrome among US women. Am J Ophthalmol 136: 318-326.

5. The epidemiology of dry eye disease: report of the Epidemiology Subcommittee of the International Dry Eye WorkShop. Ocul Surf 5: 93-107.

6. Sharpe RA, Austin JP, Kruft B, Nelson LA, Stewart JA, et al. (2015) Description of ophthalmic pharmaceutical and device start-up companies. Ophthalmic Res 54: 6-9.

7. Ciccone MM, Aquilino A, Cortese F, Scicchitano P, Sassara M, et al. (2010) Feasibility and effectiveness of a disease and care management model in the primary health care system for patients with heart failure and diabetes (Project Leonardo). Vasc Health Risk Manag: 6: 297-305. 